\title{
Trends and Inequality in the New Active Ageing and Well-Being Index of the Oldest Old: a Case Study of Sweden
}

\author{
Johan Fritzell ${ }^{1}$ (D) Carin Lennartsson $^{1}$ (D) $\cdot$ Asghar Zaidi ${ }^{2,3,4,5}$ (D)
}

Received: 14 December 2018 / Accepted: 22 January 2020 / Published online: 24 February 2020

(C) The Author(s) 2020

\begin{abstract}
The policy discourse on active ageing and well-being at the European level tends to have a strong focus on the experiences of the 'young old'. In this study the focus instead is on the oldest old (75 years and older). The theoretical framework is inspired by the Active Ageing Index and the Nordic welfare research tradition. Active ageing and well-being indicators and domains of high relevance for the oldest old are used and a new Active Ageing-Well Being Index (AA-WB Index) is developed. Our aim is to go beyond averages and analyse changes over time and inequality in the AA-WB Index. The prime data is derived from two waves, 2004 and 2014, of the Swedish Panel Study of Living Conditions of the Oldest Old (SWEOLD), a nationally representative sample of older people. The results show an overall improvement in most domains of the AAWB index, especially in the indicator participation in cultural and leisure activities. The findings also show clear and consistent gender and educational inequalities. In addition, the different domains correlate, implying that inequality within a domain is aggravated by the inequality in another domain. The study highlights that measurements on active ageing and well-being should place a greater importance on the living conditions of the oldest old with a special focus on inequality.
\end{abstract}

Keywords Active ageing · Oldest old · Wellbeing $\cdot$ Inequality $\cdot$ Multidimensionality

\section{Introduction}

The rapid increase of the number of oldest old persons in most countries is formidable and have serious implications for health and social care services. In Sweden, for example, the number of persons 75 years or older have increased by a staggering $270 \%$ since 1960 . In the same vein, for persons of age 85 years or older the percentage increase is a further doubling

Johan Fritzell

Johan.Fritzell@ki.se

Extended author information available on the last page of the article 
of that number. Demographic prognoses clearly indicate a continuation of these trends in the future. At the European Union level, the statistics available on the proportion of people aged 80 or more show a more than doubling between 2016 and 2050 (European Commission 2017). These changes in the age structure and the impending changes in how societies are organised can be seen as a major societal challenge. In particular, the social protection programmes, both in cash and kind, are put under severe pressure by these fundamental demographic changes and highlight the importance of strategies promoting active and healthy ageing (Walker and Zaidi 2019).

To a large extent, this general approach of promoting a positive approach to ageing is also pursued by a number of international organisation, such as World Health Organisation's recent focus on Healthy Ageing (2015) and the European Commission designation of 2012 as the European Year for Active Ageing and Solidarity between Generations. It was also under the work programme of the European Year 2012 that the Active Ageing Index was developed (Zaidi and Stanton 2015; Zaidi et al. 2013, 2017). It is however noteworthy that the Active Ageing Index (AAI) and perhaps in particular the European policy discourse about active ageing tend to have a stronger focus on the conditions of the 'young old'. As a result, a major concern is with important issues such as the labour force participation rates at various ages between 55 and 74, and the intense labour market and social policy discussions about the necessity of extending working careers.

For people aged 75 and above, their present relationship to the labour market is of lesser concern. It is at these ages a tremendous growth of populations is observed, especially when looking into the future. The knowledge about the state of health and other important living conditions and how they are changing, not to speak about inequalities among the old, is quite rudimentary both looking from a research perspective and for national and international evidence for policy making purposes. For sure, there is a lot of additional medical research focusing on the incidence and prevalence of certain diseases but a more comprehensive description of living conditions of this age group is quite rare. The inequalities between men and women at the higher ages are also of concern, partly because of differential gender roles during earlier parts of the life course. Looking at the official statistics one can also note one further limitation: Statistical offices seldom present indicators for the oldest old but rather suffice with either showing indicators for all persons aged 65 or above or alternatively only for the age category 65-79, as has been highlighted recently by United Nations (2018).

Our aim in this paper is to discuss, explore and adjust indicators of active and healthy ageing and wellbeing for the oldest old (75+) in Sweden. Our theoretical framework is inspired by the AAI as well as by the Nordic welfare research tradition in which a multidimensional approach is adopted in order to capture people's level of living (Fritzell and Lundberg 2005). We carry out this research using some official statistics but the prime data is derived from the Swedish Panel Study of Living Conditions of the Oldest Old (SWEOLD), a nationally representative sample of older persons living in Sweden (see below for more details). The survey follows the Nordic welfare research tradition in having a multidimensional approach including indicators of health and care, economic resources, family and social relations, activities of daily living etc.

It is not self-evident how to conceptualise and operationalise the 'oldest old' and several different age groups have been used in earlier research and policy documents. In 
this study the 'oldest old' is operationalised as 75 years and older. The first aim is to develop the analytical framework of dimensions and indicators of relevance for the oldest old, from the background of both the AAI research and by taking the perspective of the Swedish welfare research tradition. We therefore label our new composite index as the Active Ageing-Well Being Index (AA-WB Index). The second aim is to present empirical findings using aggregated results from analysis of the selected domains and their indicators for Swedish persons aged 75 and older. The third aim is to reflect on dynamics by reviewing how the indices developed in this paper have changed over time looking at data from around 2004 comparing to data from around a decade later. Finally, another, rather novel, aim is to go beyond averages and proportions and analyse inequality in the AA-WB Index stratified by gender and socio-economic position.

The last mentioned aim is of increasing importance in social policy circles since increasing inequalities in the core indicators such as income and health are observed among older adults in many countries. For this purpose, we will not only look at inequalities within a domain but inequality will also be evaluated from how these domains are correlated at the microlevel of individuals. The emphasis on highlighting inequalities is of particular importance in targeting public social services. The case study for Sweden will provide the inspirations and requirements of the AA-WB Index to be developed in the future for other European and Asia-Pacific countries.

\section{Theoretical Background of the Nordic Command over Resources Approach}

In the Nordic countries, there is a long tradition of measuring welfare and level of living in terms of living conditions in many different life domains including both material and non-material resources.

Level of living is understood as 'the individual's command over resources in the form of money, possessions, knowledge, mental and physical energy, social relations, security, etc., through which the individual can control and consciously direct his living conditions' (Johansson 1970:25).

In this definition one can note the inspiration from the seminal writings of Richard Titmuss (1958) on "command over resources". The definition rests on a number of important theoretical features (Fritzell and Lundberg 2007).

-First, it is based on a view of humans as active agents, and stands in contrast to viewing humans as passive consumers of goods and services, through which their needs are satisfied. Resources like health, money or a good education, are essential in that they increase the possibilities of action.

-Second, the ultimate good life is not defined and measured, instead the focus is avoiding lack of resources and related negative conditions. The idea is that by ensuring people's access to a wider set of resources, they are enabled to form a good life according to their own preferences.

-Third, welfare is seen as a multidimensional concept and the dimensions are seen as non-comparable or at least difficult to compare. Thereby clashing with welfare economics and the idea of GDP as the ultimate one-dimensional measure of welfare. It is more in line with the discussion within EU about social inclusion indicators (Atkinson et al. 2002) and have many similarities with Amartya Sen's writings on welfare and well-being (Sen 1985, 1992). 
The focus on resources, rather than needs, calls for objective indicators of living conditions instead of measures of the degree of satisfactions with these conditions. Thereby, people's actual conditions are in focus, not their subjective assessments of these conditions.

The level of living was then divided into nine components:

i. Health and access to care;

ii. Employment and working conditions;

iii. Economic resources;

iv. Knowledge and educational opportunities;

v. Family and social relations;

vi. Housing and neighbourhood facilities;

vii. Security of life and property;

viii. Recreation and culture;

ix. Political resources.

In extending this work to other European countries, the broad, multi-purpose surveys, such as the EU Survey of Income and Living Conditions (EU-SILC) and the Eurofound's European Quality of Life Surveys (EQLS), will be of great importance in the collection of information on the oldest age groups. A boosting of the sample size of the oldest old age group sometimes will be necessary to ensure credibility in capturing the oldest age categories.

It seems reasonable that certain dimensions of life, e.g. health and access to care, becomes even more central for the oldest old, we therefore split this dimension into two. On the other hand, the dimension employment and working conditions becomes almost irrelevant. Since we focus on inequalities, education is used as a stratification variable rather than a dimension. We expand the dimension political resources to also include other important variables in line with the AAI. Due to data constraints two dimensions are excluded: Housing and neighbourhood facilities and security of life and property. All in all, indicators based on six dimensions are used, namely: 1) Economic resources; 2) Participation in activities; 3) Health resources; 4) Access to care; 5) Family and social relations; and 6) Participation in society.

It should be noted that the overall goal of the Nordic welfare research tradition is somewhat different from the objectives pursued in the AAI. While the latter include many key aspects of welfare and well-being, the overall focus is on how older persons contributes to society and to what extent the prerequisites for participation in society and well-being for older persons exist in the country. In all likelihood, an improvement in the AAI value for a country would imply on average an increase of well-being, but no one to one relationship can be implied. An example of the opposite is that all citizens will not automatically see an increase of stipulated retirement age leading to higher employment as also an improvement in their well-being. A related example is that high employment rate among older persons is a constrained choice arising due to lack of adequate levels of pensions in the country. Hence, in our effort towards capturing both active ageing and well-being, the dimensions included are different from the ones adopted in developing the AAI, still many inherent commonalities can be identified. It can be argued that the multidimensional studies starting from very different theoretical perspectives actually often end up having many similarities in dimensions and indicators linked to well-being and welfare. 


\section{Inequality Dimensions}

The AAI has its strength in that it allows comparison within and between countries and over time. As such it gives averages but not how the extent of active ageing varies across the social structure within a single society (an exception can be seen in the analysis of differences in the AAI across educational groups, cf. Zaidi and Unt 2018). In this paper, we will also present the extent to which the AA-WB index varies by education and gender. While ample evidence exists of inequalities in different living conditions among the population at large, the knowledge is much more limited when focusing on the subgroups within the oldest old age group. In fact, one of the main theories around health inequalities in old age, the so-called "age-as-leveler" hypothesis suggests that inequalities will level of mainly due to biological processes becoming more important and due to the fact that people in old age are no longer exposed to labour market processes of social stratification (Hoffmann 2011).

A common feature of major bulk of inequality studies is that they focus on only one single indicator or - less common - on one life domain typically analysing the risk of certain bad conditions such as ill health, poverty or social isolation. In this paper, we also analyse how different domains are interrelated (see Heap et al. 2018 for a similar approach), addressing the question: Are they the same people who have poor conditions in different domains or are they separate and unrelated events. An evaluation of the extent and nature of inequality is arguably very different if the same persons are poor, in bad health, socially isolated etc. rather than the opposite (Walzer 1983; Sen 1992). Esping-Andersen puts it well: "Where the risk view tends to see welfare problems as discrete manifestations, the resource view emphasizes how resources (and welfare conditions) bundle together. In fact, it is the welfare correlates that matter." (Esping Andersen 2000, pp. 6-7).

\section{Material and Methods}

\section{Data}

The study is based on data from the Swedish Panel Study of Living Conditions of the Oldest Old (SWEOLD), a nationally representative sample of people aged 76 years and older living in Sweden. The survey has been conducted in 1992, 2002, 2004, 2011 and 2014 (see Lennartsson et al. 2014 for details). The SWEOLD sample was extracted from the sample in the Swedish Level of Living Survey, (LNU) a national random probability study of 6000 adults aged 18-75 originally fielded in 1968, with repeated panels in 1974, 1981, 1991, 2000, and 2010 (for details see Fritzell and Lundberg 2007; Evertsson and Magnusson 2014). The LNU dropped subjects from subsequent panels when they turned 76 years of age. The SWEOLD sample includes all individuals who were in the sample, but who were dropped due to the age ceiling restriction. The response rate is over $80 \%$ in all waves (Lennartsson et al. 2014). We use information from SWEOLD 2004 and 2014 but if information is lacking from these particular years information from another interview in the adjoining waves is used. To avoid high non- 
response, due to poor health or impaired cognition and to keep the data nationally representative mixed interview methods and indirect (proxy) interviews are used. Indirect interviews were carried out if the person was not able to answer questions by any of the offered interview methods. The most common reasons for an indirect interview being required were dementia or frailty, which can occur more often in oldest age groups covered in this paper. Indirect interviews were conducted either with close relatives or health care personnel. For the purpose of this paper we would especially like to highlight the importance of including also those most frail, persons living in institutions and more generally to have a high response rates. If not the risk of evaluating societal changes based on a selective sample of those most active and healthy is impending.

\section{Domains and Indicators}

The variables selected to represent the command over resources are categorised in six domains and the indicators constituting these domains are described below. We would like to stress here that this categorization is not to be regarded as definite but rather as a first attempt to capture dimensions of importance to the oldest old and adopt the prime data to the approach used in the AAI. Note also that, as in the AAI construction, all indicators are measured in positive terms so that higher values represents better outcomes.

\section{Economic Resources}

Cash Margin Cash margin was operationalised in terms of a financial buffer. Respondents were asked if they could come up with a certain sum of money in a week's time. The sum was adjusted to have the same purchase value in all survey years and corresponded to, 12,000 SEK in 2002, and 14,000 SEK in 2011 and 2014. People were considered to have financial resources if they were able to come up with the money by drawing on their own resources, through a withdrawal from their own bank account or selling stocks and shares.

Indicator $1.1=$ Proportion with cash margin

Financial Difficulties Financial difficulties was measured by the question: Have you at any time over the last 12 months had difficulties managing your current expenses for food, rent, bills, etc.? Those who are answering yes to this question are considering to have financial difficulties. The response to this question was reversed to achieve the positive indicator.

Indicator $1.2=$ Proportion with no financial difficulties

At-Risk-of-Poverty At-risk-of-poverty was measured as having equivalent disposable income below $60 \%$ of national median income (data extracted from Statistics Sweden database 2018).

Indicator $1.3=$ Proportion with income above the at-risk-of-poverty threshold 


\section{Participating in Activities}

Cultural and Leisure Activities This dimension includes different social engagement activities. The question: 'Do you usually do any of the following?' was followed by a list of activities, including going to movies, theatre, concerts, museums, exhibitions; going on trips or excursions; eating out at restaurants. These questions had three response categories that were scored "no" (0), "yes sometimes" (1), and "yes often" (2), and summed to form scales.

Indicator $2.1=$ Proportion that participate at least sometimes on two cultural and leisure activities

Physical Activities Physical activities were operationalised as from a question on outdoor activities such as sports, walks, bicycling. These questions had three response categories that were scored "no" (0), "yes sometimes" (1), and "yes often" (2), and summed to form scales.

Indicator 2.2 = Proportion that are physically active at least sometimes or often

\section{Health Resources}

Mobility dimension was operationalised in terms of the ability to move about (e.g. walking $100 \mathrm{~m}, 500 \mathrm{~m}$ and climb stairs).

Indicator $3.1=$ Proportion with no mobility restrictions

Activity of Daily Living (ADL) were measured as the ability to perform various tasks that are required in daily living, such as visiting the toilet, being able to (un)dress, eating, washing their hair, and getting in and out of bed.

Indicator $3.2=$ Proportion able to perform all these ADL tasks

The Mental Health index contained three indicators of mental health issues all indicators were drawn from the question 'Have you had any of the following illnesses or ailments during the past 12 months?' This was followed by a list of specific health problems. Response alternatives were 'Yes, severe', 'Yes, slight' and 'No'. Mental health was assessed with an index of three questions, one on nervousness problems (anxiety), one on depression/deep sadness and one of mental illness. Those who reported either no or one slight problem on the first two questions and no on the third question were classified having good mental health.

Indicator $3.3=$ Proportion with good mental health

Remaining Life Expectancy at Age 75 Target set at 30 (to align with the AAI index). Remaining life expectancy at age 75 was 10.4 years for men and 12.7 years for women in 2004 and 11.4 years for men and 13.4 years for women in 2014 (data extracted from Statistics Sweden 2018). 
Indicator $3.4=$ Share of the target of remaining life expectancy of 30 years at age 75

\section{Access to Care}

Access to Medical Care is central aspect of individual welfare. Among older people, the need and use of care is generally higher than among younger age groups. The question for access to medical care is: Have you at any time during the last 12 months, refrained from visiting a medical doctor though you needed to?

Indicator 4.1 = Proportion who has not refrained from seeking medical care

Access to Dental Care is based on the question: Have you at any time during the last 12 months, refrained from visiting a dentist though you needed to?

Indicator 4.2: Proportion who has not refrained from seeking dental care

\section{Family and Social Relations}

Living Alone or not, those living in institutions were considered to live alone.

Indicator 5.1: Proportion who do not live alone or in an institution

Social Contacts with Children and/or Grandchildren were measured with questions on frequency of spending time with children and grandchildren. Respondents were asked about how often they met and spent time with their children, and how often they met and spent time with their grandchildren/great grandchildren. Response alternatives were 'Daily', 'Several times a week', 'A few times a week', 'A few times a month', 'A few times a quarter', and 'Seldom or never'. Those who reported having children or grandchildren and having monthly contact or more was regarding having family contacts.

Indicator 5.2: Proportion having family contacts

Social Contacts with Relatives and Friends were measured with the question do you usually visited relatives, usually had relatives over for visits, usually visited friends/ acquaintances, and usually had friends/acquaintances over for visits. Response alternatives were 'No', 'Yes, sometimes', and 'Yes, often'. Those who visiting or being visit by relatives/friends at least sometime on two of the four questions are regarding having social contacts with relatives and friends.

Indicator 5.3: Proportion having social contacts

\section{Participation in Society}

Care Provision To capture activities of older adults in terms of care provision to other older adults in form of personal care, household tasks, or supervisions. The questions were only asked to those cohabiting in ordinary housing or service flat: 
Do you help your wife/husband/cohabitant with personal care such as bathing/ showering, dressing, getting into/out of bed and/or supervision? Do you help an older relative (not living with you) with personal care, household tasks or supervision, on a regular basis?

Indicator 6.1: Proportion caring for an older person monthly or more often

Political Participation reflects another important type of resource. In a society where everyone has the legal right to express their views and take political action, political resources are important means for individuals to influence their living situation (Johansson 1970). Furthermore, it may indirectly capture an ability to navigate societal and political systems, such as people's 'health literacy' (Stocks et al. 2009) which contributes to inequality in health services utilisation. Political participation was measured by four items.

Voting was based on the question "Did you vote in the last election? Those who answered "yes" were considering voting.

Indicator 6.2: Proportion voted in the last election

Active Member of an Organisation The second indicator is the degree of involvement in more organised activities by the reported frequency of participation in the meetings of voluntary organizations, such as those serving retired persons, or those organized by a political party or religious organization. Those who are a member and participating in these organisations a few times a year were considered to be an active member of an organisation.

Indicator 6.3: Proportion active in organisation(s)

Letter of Appeal The first question concerns whether or not the respondent is able to, by him/herself, write a letter to appeal a decision made by a public authority. Response alternatives were 'Yes' and 'No'. If the respondent answered 'No', this was followed up by a question concerning whether or not the respondent has anyone who can help him/ her write a letter of appeal. If a person answered 'Yes' to one of these questions, he/she was considered to appeal a decision made by a public authority.

Indicator 6.4: Proportion who managed to appeal

Reading Newspaper The question: 'Do you usually do any of the following?' was followed by a list of activities, including reading newspaper. The response alternatives were 'No', 'Yes, sometimes' and 'Yes, often'. Those who respond 'Yes often' to this question were considered to be reading newspaper.

\section{Indicator 6.5: Proportion reading newspaper}

As the socio-economic indicator to analyse inequalities educational level is used. Given that the educational expansion in Sweden happened after the birth cohorts of the sample went to school education is dichotomised, separating those with up to grade school from those with education beyond grade school. 


\section{Importance and Weights}

The weights used in the calculation of the AAI were drawn from the consultation process with the AAI Expert Group. Here, in the calculation of AA-WB index, no such consultations have been undertaken, nor did we make any assumption regarding the relative importance of individual indicators or the domains - to phrase it more concretely equal weights are assigned to each domain and to an individual indicator within a domain.

\section{Results}

Table 1 shows the overall, aggregated results for each indicator within each domain. As mentioned above, for the great majority of all indicators we use data from SWEOLD for 2004 and 2014. Most of the indicators show either stability or improvement but not all indicators. In particular, and somewhat surprisingly, the proportion physically active and the proportion caring for others have decreased slightly. The risk of relative poverty (AROP) has increased corroborating Eurostat data, a trend highlighted in various Commission reports over the last years. Over basically the same time period Sweden was one out of three countries within EU28 that had clear increases observed in the atrisk-of-poverty "AROP” (European Commission 2015).

Remarkably, an increase is observed in cultural and leisure activities, which is often viewed as a string component of wellbeing in later life (Age UK 2017). An improvement in the voting behaviour and in writing a letter to appeal a decision made by a public authority are good positive signs for the social participation of oldest old in Sweden.

Figure 1 presents the domain specific AA-WB index. None of the six domains show deterioration but given that the indicators of economic resources go in different directions this domain ends up in exactly the same number for the two time periods. This result shows that one should not restrict drawing conclusions from the aggregated results alone. As mentioned above the Nordic welfare research tradition has been reluctant to summarize different domains into one index but if we still do that from the results presented in Fig. 1 it shows an improvement from 66,3 to 69,9.

The general AAI Index has highlighted a clear gender difference for almost all EU countries and for most of the four domains included. However, the difference is especially noted for the employment domain which is excluded from this study since we focus on the oldest old. It is therefore not self-evident that similar results are found in the analysis.

Table 2 gives the indicators and the AA-WB index broken down by gender. Despite the fact that we disregard the labour market we actually find quite startling differences. Women have lower scores practically in all domains. Looking at changes over time the outcomes are somewhat different depending on indicators and domains. The growing gender gap in relative poverty rates is not at all reflected in the more direct indicators of economic hardship, which instead suggest smaller gender differences. The gender gap in the health indicators are mostly stable over time.

We finally turn to the question of differences by education among the oldest old. In Table 3 and Fig. 2 this is scrutinized. The at-risk-of-poverty for the two education 
Table 1 AA-WB indicators and their measures within six domains for the oldest old (75+) in Sweden 2002/2004 and 2011/2014

\begin{tabular}{|c|c|c|c|}
\hline & & $2002 / 2004$ & $2011 / 2014$ \\
\hline \multirow[t]{3}{*}{ 1. Economic resources } & 1.1 Cash-margin & 81.4 & 85.9 \\
\hline & 1.2 No financial difficulties & $97.5^{*}$ & 97.3 \\
\hline & 1.3 Not at risk-of-poverty & $88.2^{\wedge}$ & $84.5^{\wedge}$ \\
\hline \multirow[t]{2}{*}{ 2. Participation in activities } & 2.1 Culture/leisure activities & 31.4 & 50.6 \\
\hline & 2.2 Physical activities & 58.8 & 54.4 \\
\hline \multirow[t]{5}{*}{ 3. Health resources } & 3.1 Mobility & 37.0 & 45.9 \\
\hline & 3.2 Mental health & 87.0 & 88.2 \\
\hline & 3.3 Activity of daily living & 74.9 & 77.7 \\
\hline & 3.4 Self-rated health & 42.4 & 42.7 \\
\hline & 3.5 Life-expectancy at 75 & $38.4^{\wedge}$ & $41.3^{\wedge}$ \\
\hline \multirow[t]{2}{*}{ 4. Access to care } & 4.1 Medical care & $89.3^{*}$ & $89.5^{* *}$ \\
\hline & 4.2 Dental care & $91.6^{*}$ & 94.9 \\
\hline \multirow[t]{3}{*}{ 5. Family and social relations } & 5.1 Cohabiting & 36.5 & 44.2 \\
\hline & 5.2 Family contacts & 72.8 & 76.5 \\
\hline & 5.3 Social contacts & 68.9 & 76.4 \\
\hline \multirow[t]{5}{*}{ 6. Participating in society } & 6.1 Care for older people & 11.4 & 8.8 \\
\hline & 6.2 Voting & $75.2 *$ & 84.4 \\
\hline & 6.3 Active in organisation & $38.9 *$ & $37.8 * *$ \\
\hline & 6.4 Writing letter of appeal & $85.4^{*}$ & 93.4 \\
\hline & 6.5 Reading newspaper & 78.8 & $79.0 * *$ \\
\hline
\end{tabular}

*Sweold 2002 (age 77-)

**Sweold 2011 (age 76-)

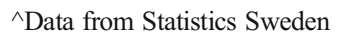

groups was not accessible at the time of production of this paper and due to data constraints the life-expectancy indicator was calculated from age 65. Looking at individual indicators of the first domain, one finds small differences in most cases. However, in the second domain, those with higher than basic education are much more participatory than those with up to basic level of education. The same result is found for indicators in the third domain, except for the mental health indicator in the base year (2002/2004). There is only small difference in the indicators of the fourth domain, access to care.

Figure 2 summarize how large the educational inequality scores are for each domain and how they have changed. Notable is first that for all domains in both time periods educational inequalities are present, second for most domains there is signs of increasing inequalities in the AAI-WB index.

\section{Correlations between Different Domains}

The results presented above show clearly educational and gender inequalities in the domains. Our second approach to inequality goes beyond the risk perspective 


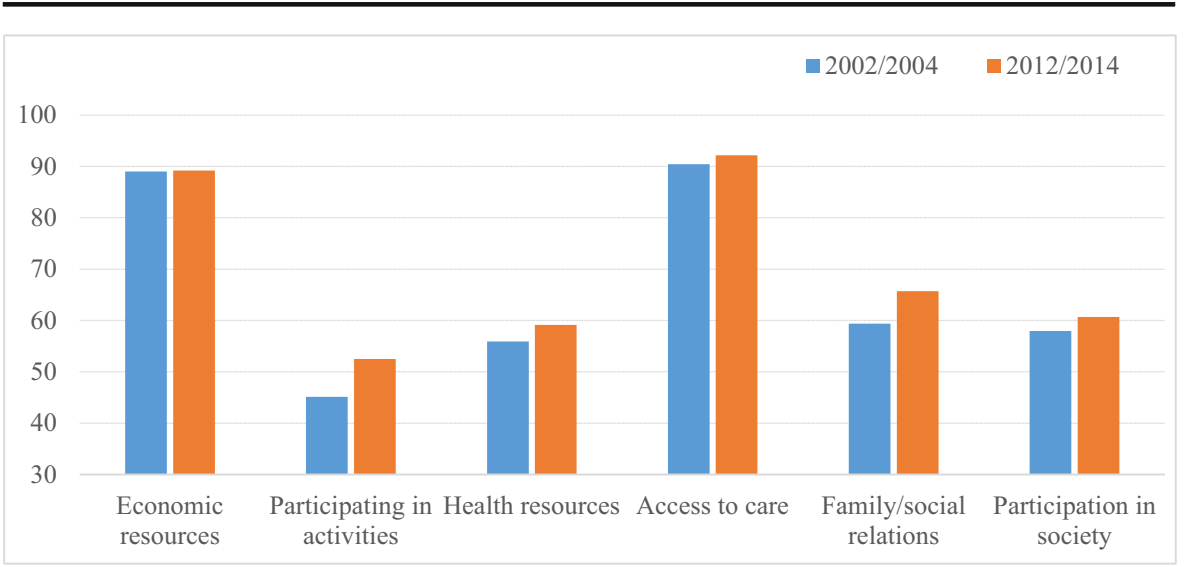

Fig. 1 Active Ageing -Well Being Index domain specific scores for older persons (75+) in Sweden between $2002 / 04$ and $2011 / 2014$

of analysing each domain separately. To grasp more fully the extent of inequality we adopt a more holistic approach and simultaneously study these dimensions. We do so using a relatively simple method of analysing the correlations between dimensions. Since only categorical variables are used, correlations with gamma coefficients are presented in Table 4 . Given the relatively small sample, one should not put too much weight of small differences between different pairs of domains. Instead, the overall picture is striking: all the 30 presented correlations are positive, meaning that a better outcome in one domain is linked to a better outcome in another domain (and vice versa). The most striking correlation is between the domains of 'health resources' and 'access to care' on the one hand, and 'participation in activities' on the other.

\section{Synthesizing Discussion}

Looking at this paper's empirical findings, a slight overall improvement in most indicators and domains of active ageing and well-being can be observed during the period between 2002/2004 and 2011/2014. This is particularly evident in the case of participation in cultural and leisure activities of the oldest old Swedes. In interpreting the results of inequalities, it is sometimes argued that inequalities become less evident or disappear at older ages, say due to selective mortality (Dupre 2007). The findings of this study point to the opposite: they highlight a clear and consistent pattern of gender and educational inequalities in our AA-WB indices. This is despite the fact that the analysis is based on the case study of Sweden, with its well-known ambition for both socioeconomic and gender equality. This is further reinforced by the results from the analysis how the dimensions studied correlate to each other. A negative correlation would, in a sense, imply that poor outcome within one domain is compensated by better outcome in another domain. However, in the analysis presented in this paper, all thirty estimated correlations are in fact positive (in statistical terms), implying that those individuals with poor conditions in one respect also are more likely to experience poor conditions in another domain. 
Table 2 Gender differences in the six domains for the oldest old in Sweden 2002/2004 and 2011/2014

\begin{tabular}{|c|c|c|c|c|c|}
\hline & & $\begin{array}{l}2002 / \\
2004\end{array}$ & $\begin{array}{l}2002 / \\
2004\end{array}$ & $\begin{array}{l}2011 / \\
2014\end{array}$ & $\begin{array}{l}2011 / \\
2014\end{array}$ \\
\hline & & Women & Men & Women & Men \\
\hline \multirow[t]{3}{*}{ 1. Economic resources } & 1.1 Cash-margin & 76.1 & 89.6 & 84.4 & 87.8 \\
\hline & 1.2 No financial difficulties & $96.7^{*}$ & $98.8^{*}$ & 96.6 & 98.3 \\
\hline & 1.3 Not at risk-of-poverty & 86.2 & 91.9 & 80.3 & 91.5 \\
\hline Overall score & & 86.3 & 93.4 & 87.1 & 92.5 \\
\hline \multirow[t]{2}{*}{ 2. Participation in activities } & 2.1 Culture/leisure activities & 29.2 & 34.7 & 45.0 & 58.4 \\
\hline & 2.2 Physical activities & 53.4 & 67.1 & 49.4 & 61.4 \\
\hline Overall score & & 41.3 & 50.9 & 47.2 & 59.9 \\
\hline \multirow[t]{5}{*}{ 3. Health resources } & 3.1 Mobility & 29.1 & 49.5 & 40.7 & 53.1 \\
\hline & 3.2 Mental health & 84.1 & 91.3 & 84.9 & 92.7 \\
\hline & 3.3 Activity of daily living & 71.5 & 80.1 & 74.3 & 82.5 \\
\hline & 3.4 Self-rated health & 40.0 & 46.2 & 40.4 & 46.0 \\
\hline & 3.5 Life-expectancy at $75^{\wedge}$ & 42.3 & 34.7 & 44.7 & 38.0 \\
\hline Overall score & & 53.4 & 60.4 & 57.0 & 62.5 \\
\hline \multirow[t]{2}{*}{ 4. Access to care } & 4.1 Medical care & $89.6^{*}$ & $88.9^{*}$ & $88.4 * *$ & $91.3 * *$ \\
\hline & 4.2 Dental care & $91.6^{*}$ & $91.6^{*}$ & 93.9 & 96.3 \\
\hline Overall score & & 90.6 & 90.3 & 91.2 & 93.8 \\
\hline \multirow[t]{3}{*}{ 5. Social relations } & 5.1 Cohabiting & 24.5 & 55.2 & 31.8 & 61.5 \\
\hline & 5.2 Family contacts & 73.4 & 71.9 & 77.7 & 74.8 \\
\hline & 5.3 Social contacts & 68.6 & 69.3 & 73.8 & 80.2 \\
\hline Overall score & & 55.5 & 65.5 & 61.1 & 72.2 \\
\hline \multirow[t]{5}{*}{ 6. Participating in society } & 6.1 Care for older people & 10.9 & 12.0 & 8.0 & 10.0 \\
\hline & 6.2 Voting & 69.7 & 83.3 & 80.1 & 84.4 \\
\hline & 6.3 Active in organisation & $37.6^{*}$ & $40.9 *$ & $36.9 * *$ & $39.4 * *$ \\
\hline & 6.4 Writing letter of appeal & $83.6^{*}$ & $87.9^{*}$ & 93.4 & 92.4 \\
\hline & 6.5 Reading newspaper & 74.9 & 84.8 & $75.9 * *$ & $84.4^{* *}$ \\
\hline Overall score & & 55.3 & 61.8 & 58.9 & 62.1 \\
\hline
\end{tabular}

*Sweold 2002 (age 77-)

**Sweold 2011 (age 76-)

^Data from Statistic Sweden

From a theoretical perspective the marked differences by gender and education should be understood from a life course perspective. Women and low educated persons may have, on average, a subordinate position, and such life course patterns will then have repercussions well beyond the working age. Hence, it is not surprising that the impact of working conditions for various welfare aspects of later life have been studied extensively in the literature (Andel et al. 2011). Likewise, other aspects of life leading to lower command over resources are also likely to explain our results suggesting that the social segmentation processes are still operating at higher ages. Moreover, the socioeconomic inequalities in survival are substantial also at older ages (Rehnberg et al. 
Table 3 Educational differences in the six domains for the oldest old in Sweden 2002/2004 and 2011/2014

\begin{tabular}{|c|c|c|c|c|c|}
\hline & & $\begin{array}{l}2002 / \\
2004\end{array}$ & $\begin{array}{l}2002 / \\
2004\end{array}$ & $\begin{array}{l}2011 / \\
2014\end{array}$ & $\begin{array}{l}2011 / \\
2014\end{array}$ \\
\hline & & Basic education & $\begin{array}{l}\text { Above basic } \\
\text { education }\end{array}$ & $\begin{array}{l}\text { Basic } \\
\text { education }\end{array}$ & $\begin{array}{l}\text { Above } \\
\text { basic } \\
\text { education }\end{array}$ \\
\hline \multirow{3}{*}{$\begin{array}{l}\text { 1. Economic } \\
\text { resources }\end{array}$} & 1.1 Cash-margin & 78.1 & 88.1 & 84.5 & 89.2 \\
\hline & 1.2 No financial difficulties & $98.0^{*}$ & $96.9^{*}$ & 96.9 & 97.9 \\
\hline & 1.3 Not at risk-of-poverty & & & & \\
\hline \multirow{2}{*}{$\begin{array}{l}\text { 2. Participation } \\
\text { in activities }\end{array}$} & 2.1 Culture/leisure activities & 21.9 & 48.8 & 37.0 & 66.3 \\
\hline & 2.2 Physical activities & 52.9 & 69.4 & 42.9 & 67.2 \\
\hline \multirow{5}{*}{$\begin{array}{l}\text { 3. Health } \\
\text { resources }\end{array}$} & 3.1 Mobility & 33.0 & 44.0 & 37.5 & 55.4 \\
\hline & 3.2 Mental health & 86.7 & 79.8 & 89.1 & 87.9 \\
\hline & 3.3 Activity of daily living & 72.2 & 79.8 & 71.5 & 85.5 \\
\hline & 3.4 Self-rated health & 38.8 & 48.8 & 32.2 & 54.1 \\
\hline & 3.5 Life-expectancy at $65^{\wedge}$ & 46.5 & 50.3 & 48.5 & 52.8 \\
\hline \multirow{5}{*}{$\begin{array}{l}\text { 4. Access to } \\
\text { Care } \\
5 \text {. Social } \\
\text { relations }\end{array}$} & 4.1 Medical care & $89.2 *$ & $90.3^{*}$ & $87.6^{* * *}$ & $92.1 * *$ \\
\hline & 4.2 Dental care & $90.4^{*}$ & $94.3^{*}$ & 94.6 & 95.9 \\
\hline & 5.1 Cohabiting & 33.9 & 40.9 & 39.3 & 49.9 \\
\hline & 5.2 Family contacts & 73.6 & 71.5 & 80.0 & 72.7 \\
\hline & 5.3 Social contacts & 68.9 & 68.3 & 71.1 & 82.1 \\
\hline \multirow{5}{*}{$\begin{array}{l}\text { 6. Participating } \\
\text { society }\end{array}$} & 6.1 Care for older people & 11.1 & 12.0 & 8.7 & 9.2 \\
\hline & 6.2 Voting & $70.3^{*}$ & $86.5^{*}$ & 78.5 & 90.3 \\
\hline & 6.3 Active in organisation & $34.1 *$ & $49.2^{*}$ & $30.8 * *$ & $47.1^{* *}$ \\
\hline & 6.4 Writing letter of appeal & $82.9 *$ & $90.1 *$ & 89.8 & 95.9 \\
\hline & 6.5 Reading newspaper & 77.7 & 82.1 & $77.9 * *$ & $81.9 * *$ \\
\hline
\end{tabular}

*Sweold 2002 (age 77-)

**Sweold 2011 (age 76-)

${ }^{\wedge}$ Data from Statistic Sweden: due to data constraints life-expectancy is calculated from the age of 65

2019). What is studied here is, in a sense, educational inequality on top of such inequalities in mortality. Our study's focus on active ageing and well-being among those surviving with selective mortality is likely to dampen such inequalities since those surviving to older ages among the lower educated are likely to be a more positively selective group in other respects (Dupre 2007).

Walzer (1983), in his theory of distributional justice, argues that we should strive for a society with 'complex equality'. By that he means that a person should not have the best outcome in one domain just because she is so in another. The simple correlation analysis presented in this paper suggest that Sweden is far from fulfilling the goal of complex equality. Instead, it can be inferred from high and systematic positive correlation coefficients to be the case that inequality within a domain may $\mathrm{h}$ aggravated by the inequality in another domain. This emphasis on the goal of complex equality reiterates that inequality in active ageing and well-being among the oldest old should be a central concern. 


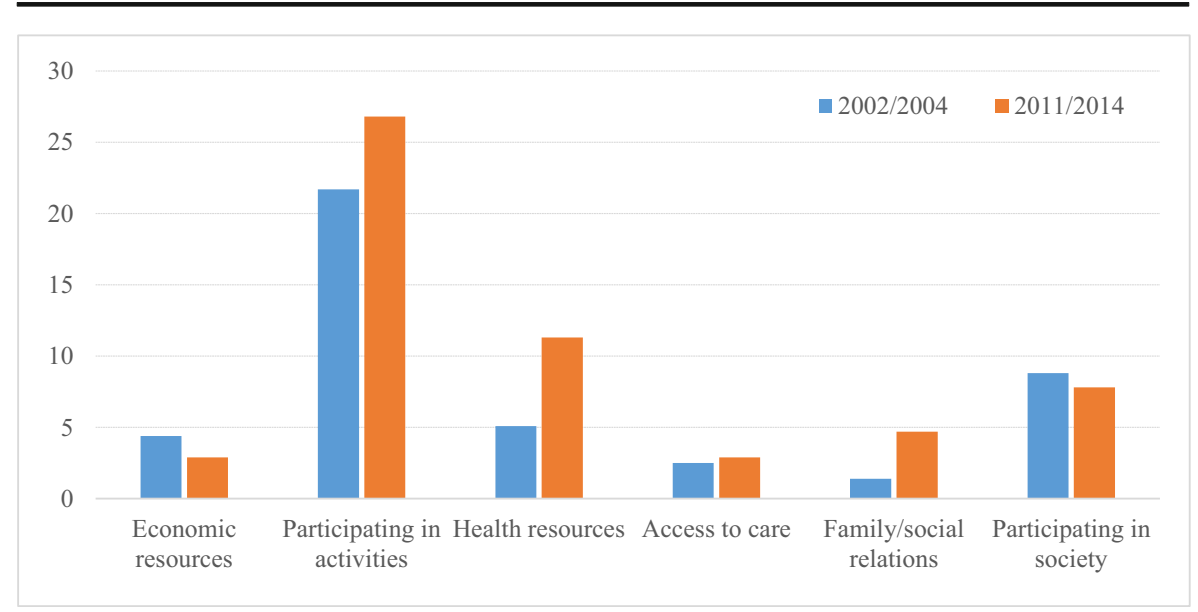

Fig. 2 Educational differences in the AA-WB Index by domains for older persons $(75+)$ in Sweden

Finally, it can be stressed here that the choice of indicators and domains in the construction of the AA-WB Index should not be regarded as definite as what we strive to measure in terms of active ageing and well-being among the oldest old is latent in many ways. We have selected indicators based on earlier theories from the Nordic welfare research tradition and from the perspective of active ageing within the AAI framework. Still, comparing our choice with these theoretical perspectives, certain important indicators may still be missing from our study. The final choice of indicators was partly pragmatic, based on the availability of data, and partly subjective.

A strength of this study is that it is based on a nationally representative sample of older people living in Sweden with a very high response rate. Accordingly, the analysed data are highly representative for the Swedish population, including sick, frail and institution-based older people (see Lennartsson et al. 2014). This inclusion is very important in our pursuit of accurate information on active ageing and well-being of the oldest old.

Furthermore, in order to make sure that the sample is representative for both institution-based and community-living older people and for all older people irrespective of their health problems, physical limitations and cognitive impairments, we also include information from indirect (proxy) interviews. Although it might be a risk that

Table 4 Correlations (gamma coefficients) between different domains. Older persons (75+) in Sweden 2014

\begin{tabular}{lllllll}
\hline & $\begin{array}{l}\text { Economic } \\
\text { resources }\end{array}$ & $\begin{array}{l}\text { Participation in } \\
\text { activities }\end{array}$ & $\begin{array}{l}\text { Health } \\
\text { resources }\end{array}$ & $\begin{array}{l}\text { Access to } \\
\text { care }\end{array}$ & $\begin{array}{l}\text { Family/ } \\
\text { Social } \\
\text { relations }\end{array}$ & $\begin{array}{l}\text { Participation } \\
\text { in society }\end{array}$ \\
\hline Economic resources & - & .33 & .36 & .53 & .37 & .39 \\
Participation in activities & - & .68 & .49 & .45 & .40 \\
Health resources & & - & .50 & .35 & .32 \\
Access to care & & & - & .47 & .27 \\
Family/Social relations & & & & - & .39 \\
Participation in society & & & & & - \\
\hline
\end{tabular}


indirect interviewees report more welfare problems and poorer quality of life in older persons than older people themselves would do (Graske et al. 2012; Moyle et al. 2012), earlier research has also highlighted that responses from indirect interviewees with good knowledge of the older person also demonstrate good consistency with responses from older people themselves (Boyer et al. 2004; McKee et al. 2002). Besides, the exclusion of those older people who are not for different reasons able to respond to an interview by themselves underestimate the extent of many welfare problem (Kelfve et al. 2013).

In sum, the study highlights that the measurement and analysis of active ageing and well-being should place a greater importance on the living conditions of the oldest old. We argue that this is particularly relevant considering the fast change in the age structure and greater needs and aspiration of the oldest old age group. Such an approach should also go beyond averages and look at distributions and inequality aspect of active ageing and well-being.

Acknowledgements Open access funding provided by Karolinska Institute. Johan Fritzell and Carin Lennartsson received financial support from the Swedish Research Council (VR) (grant number 201801922) and the Swedish Research Council for Health, Working Life and Welfare (Forte) (grant number 2016-07206). Asghar Zaidi carried out this work within the project 'Active Ageing Index- Phase III', during 2017-2018. An earlier version of this paper was presented at the Second International Seminar on the Active Ageing Index in Bilbao, September 27-28, 2018.

Open Access This article is licensed under a Creative Commons Attribution 4.0 International License, which permits use, sharing, adaptation, distribution and reproduction in any medium or format, as long as you give appropriate credit to the original author(s) and the source, provide a link to the Creative Commons licence, and indicate if changes were made. The images or other third party material in this article are included in the article's Creative Commons licence, unless indicated otherwise in a credit line to the material. If material is not included in the article's Creative Commons licence and your intended use is not permitted by statutory regulation or exceeds the permitted use, you will need to obtain permission directly from the copyright holder. To view a copy of this licence, visit http://creativecommons.org/licenses/by/4.0/.

\section{References}

Age UK (2017) Methodology of Age UK's index of wellbeing in later life. Report produced by Green, M., Iparraguirre, J., Davidson, S., Rossall, P., \& Zaidi, A. London: Tavistock House.

Andel, R., Crowe, M., Kåreholt, I., Wastesson, J., \& Parker, M. G. (2011). Indicators of job strain at midlife and cognitive functioning in advanced old age. The Journals of Gerontology Series B: Psychological Sciences and Social Sciences, 66(3), 287-291.

Atkinson, T., Cantillon, B., Marlier, E., \& Nolan, B. (2002). Social indicators. The EU and social inclusion. Oxford: Oxford University Press.

Boyer, F., Novella, J. L., Morrone, I., Jolly, D., \& Blanchard, F. (2004). Agreement between dementia patient report and proxy reports using the Nottingham health profile. International Journal of Geriatric Psychiatry, 19(11), 1026-1034.

Dupre, M. E. (2007). Educational differences in age-related patterns of disease: Reconsidering the cumulative disadvantage and age-as-leveler hypotheses. Journal of Health and Social Behavior, 48, 1-15.

Esping Andersen, G. (2000) Social indicators and welfare monitoring. Social policy and development Programme paper number 2. Geneva: UNRISD.

European Commission. (2015). The 2015 pension adequacy report: Current and future income adequacy in old age in the EU. Volumes I and II. Luxembourg: Publications Office of the European Union.

European Commission (2017) The 2018 ageing report. Underlying assumptions \& projection methodologies. Institutional Paper 065, November 2017. European Union: Luxembourg Publication Office. 
Evertsson, M., \& Magnusson, C. (Eds.). (2014). Ojämlikhetens dimensioner: Uppväxtvillkor, arbete och hälsa i Sverige. Stockholm: Liber.

Fritzell, J., \& Lundberg, O. (2005) Fighting inequalities in health and income - one important road to welfare and social development. In O. Kangas \&. J. Palme, (eds.) Social policy and economic development in the Nordic countries (pp. 164-185). UNRISD. Basingstoke: Palgrave.

Fritzell, J., \& Lundberg, O. (Eds.). (2007). Health inequalities and welfare resources: Continuity and change in Sweden. Bristol: Policy Press.

Graske, J., Fischer, T., Kuhlmey, A., \& Wolf-Ostermann, K. (2012). Quality of life in dementia care differences in quality of life measurements performed by residents with dementia and by nursing staff. Aging \& Mental Health, 16(7), 819-827.

Heap, J., Fritzell, J., \& Lennartsson, C. (2018). Associations between and coexistence of disadvantages in the oldest old people in Sweden: Patterns of change between 1992 and 2011. Journal of European Social Policy, 28(3), 197-210.

Hoffmann, R. (2011). Illness, not age, is the leveler of social mortality differences in old age. The Journals of Gerontology. Series B, Psychological Sciences and Social Sciences, 66(3), 374-379.

Johansson, S. (1970). Om levnadsnivåundersökningen (on the level of living survey). Stockholm: Allmänna förlaget.

Kelfve, S., Thorslund, M., \& Lennartsson, C. (2013). Sampling and non-response bias on health-outcomes in surveys of the oldest old. European Journal of Ageing, 10(3), 237-245.

Lennartsson, C., Agahi, N., Hols-Salén, L., Kelfve, S., Kåreholt, I., Lundberg, O., Parker, M. G., \& Thorslund, M. (2014). Data resource profile: The Swedish panel study of living conditions of the oldest old. International Journal of Epidemiology, 43, 731-738.

McKee, K. J., Houston, D. M., \& Barnes, S. (2002). Methods for assessing quality of life and well-being in frail older people. Psychology \& Health, 17(6), 737-751.

Moyle, W., Murfield, J. E., Griffiths, S. G., \& Venturato, L. (2012). Assessing quality of life of older people with dementia: A comparison of quantitative self-report and proxy accounts. Journal of Advanced Nursing, 68(10).

Rehnberg, J., Fors, S., \& Fritzell, J. (2019). Divergence and convergence: How do income inequalities in mortality change over the life course? Gerontology, 65, 313-322.

Sen, A. (1985). Well-being, agency and freedom, the Dewey lectures 1984. Journal of Philosophy, 82, 169221.

Sen, A. (1992). Inequality reexamined. Cambridge, Mass: Harvard University Press.

Statistics Sweden (2018). Extract from Statistics Sweden Database. http://www.statistikdatabasen.scb.se

Stocks, N. P., Hill, C. L., Gravier, S., Kickbusch, L., Beilby, J. J., Wilson, D. H., \& Adams, R. J. (2009). Health literacy-a new concept for general practice? Australian Family Physician, 38(3), 144-147.

Titmuss, R. M. (1958). Essays on the welfare state. London: Allen \& Unwin.

United Nations (2018). Report of the United Kingdom of Great Britain and Northern Ireland on ageing-related statistics and age-disaggregated data. United Nations Economic and Social Council, E/CN.3/2018/19.

Walker, A., \& Zaidi, A. (2019). Strategies of active ageing in Europe. In A. Walker (Ed.), The future of ageing in Europe. Singapore: Palgrave Macmillan.

Walzer, M. (1983). Spheres of justice: A Defence of pluralism and equality. New York: Basic Books.

Zaidi, A. \& Stanton, D. (2015) 'Active ageing index 2014: Analytical report', report produced at the Centre for Research on Ageing, University of Southampton, under contract with United Nations Economic Commission for Europe (Geneva), co-funded by European Commission's Directorate General for Employment, Social Affairs and Inclusion (Brussels). Available at: https:/www.southampton.ac. uk/assets/sharepoint/groupsite/Administration/SitePublisher-document-store/Documents/aai_report.pdf

Zaidi, A., \& Unt, M. (2018). The active aging index: Measuring successful aging at population level. In the Cambridge handbook of successful aging (pp. 594-609). Cambridge University press.

Zaidi, A., Gasior, K., Hofmarcher, M.M., Lelkes, O., Marin, B., Rodrigues, R., Schmidt, A., Vanhuysse, P. \& Zolyomi, E. (2013) Active ageing index 2012 concept, methodology and final results, research memorandum/ methodology report, European Centre Vienna, March 2013. Available at: www.euro. centre.org/data/aai/1253897823_70974.pdf

Zaidi, A., Gasior, K., Marin, B., Rodrigues, R., Schmidt, A., \& Zolyomi, E. (2017). Measuring active and healthy ageing in Europe. Journal of European Social Policy, 27(2), 138-157.

Publisher's Note Springer Nature remains neutral with regard to jurisdictional claims in published maps and institutional affiliations. 


\section{Affiliations}

\section{Johan Fritzell $^{1}$ • Carin Lennartsson ${ }^{1} \cdot$ Asghar Zaidi $^{2,3,4,5}$}

1 Aging Research Center (ARC), Karolinska Institutet and Stockholm University, Tomtebodavägen 18A, 17177 Stockholm, Sweden

2 College of Social Sciences, Department of Social Welfare, Seoul National University, Seoul, South Korea

3 Oxford Institute of Population Ageing, University of Oxford, Oxford, UK

4 Centre for Analysis of Social Exclusion (CASE), London School of Economics and Political Science, London, UK

5 Vice Chancellor, Government College University, Lahore, Pakistan 